\title{
Agent-Based Simulation for Evaluating the Effect of Different Walking and Driving Speed on Disaster Evacuation in Aceh
}

\author{
Sinung Widiyanto ${ }^{1}$, Dimas Adi ${ }^{2 *}$, Nadhila Nurdin ${ }^{2}$, Fadila $^{3}$
}

\begin{abstract}
Agent-Based Modeling and Simulation (ABMS) was implemented to build and develop an evacuation simulation model. In this research, ABMS is simulated in several evacuation scenarios with an output: the evacuation rate of two different decision choice evacuation modes (walking or driving to the evacuation points). The result of this tsunami evacuation simulation shows that different control parameters such as evacuation mode, percentage of car and pedestrian, walking speed and driving speed confirmed their significance on the evacuation planning in Aceh. There is a typical choice that leads to the higher evacuation rate, the choice is by maximizing the pedestrian agents on the population. Walking speed has significant importance and impact on the evacuation rate. Moderate walking speed $(4 \mathrm{ft} / \mathrm{s})$ is recommended as reference for walking speed in disaster situations. Driving speed also has a significant impact on the evacuation rate if we keep the limits at $20 \mathrm{mph}$. Since the maximum driving speed higher than $20 \mathrm{mph}$ has no impact on the evacuation rate.
\end{abstract}

Keywords - Evacuation simulation model, Tsunami, Decision choice

\section{INTRODUCTION ${ }^{1}$}

A s a country which has complex geological condition, Indonesia is located at the meeting point of two continental plates (Sunda and Australian Plate) and two oceanic plates (Philip- pine Sea and Pacific Plate). Western Indonesia even has volcanic arc as the result of the Indian oceanic plate subduction beneath the Eurasian continental plate, which has long history of powerful earthquakes and eruptions thus considered as one of the most seismically active areas on the planet [1]. Because of this reason, there were numerous tsunami potentially occurred due to the earthquakes that happened in Indonesia as shown in Fig. 1. Tsunami can occur due to undersea landslides caused by earthquakes. Furthermore, much larger and more dangerous tsunami can occur when shallow earthquakes rupture the sea floor. Thus, there a lot of tsunamis potentially occur in Indonesia particularly in the coastal areas, since Indonesia has large number of potential shallow earthquakes along the plate boundaries [2].

Indonesia experienced various natural disasters in 2019, including a series of earthquakes in West Nusa Tenggara, earthquake and tsunami in Central Sulawesi and tsunami along Sunda strait, which were claimed to kill most number of life in over a decade. Those cases are reminders for potential natural disasters that might happen in the future in Indonesia, thusinvestment on protection through disaster resilience is important to be carried out [3].

A 9.3 SR earthquake occurred near Sunda Trench, off the Sumatra Island Coast near Sunda Trench [4]. The earthquake caused an extremely large tsunami over the entire Indian Ocean leading to catastrophic damage to the coastal areas of countries around Indian Ocean, including Indonesia, Thailand, Sri Lanka, India, and even some East

\footnotetext{
${ }^{1}$ Departement of Electrical Engineering, Faculty of Engineering and Marine Sciences, Hang Tuah University, Jl. Arief Rahman Hakim No.150, Keputih, Kec. Sukolilo, Surabaya 60111, Indonesia. E-mail: sinung.widiyanto@hangtuah.ac.id

${ }^{2}$ Department of Computer Science, Faculty of Electrical Engineering, Automatics, Computer Science and Biomdedical Engineering, AGH University of Science and Technology, al. A. Mickiewicza 30, 30-059 Krakow, Poland. E-mail: dimasadi@student.agh.edu.pl
}

African countries [5]. Region Profile for Natural Disasters from $1980-2008$ [6] reported that there were more than 165 thousand Indonesian people were killed due to the disaster (approx. 0.1 percent of the country's total population). When disaster happens, it is considered as an emergency situation which should be handled through evacuation with the appropriate strategy. Evacuation on a large-scale disaster, including tsunami, must have the capability to rescue many people in a short time, thus if it is done wrongly, it will cause more deaths instead. Thus, in order to carry out optimal rescue strategy, it needs to drill evacuation. However, regular and useful drill evacuation might encounter numerous challenges and limitations, including in terms of its practical and financial. These issues can be overcome by implementing Agent-based Modeling to build and develop evacuation simulation model. Such a system has benefits of simulating the evacuation in real system without any risk since it is experimented in-silico world [7].

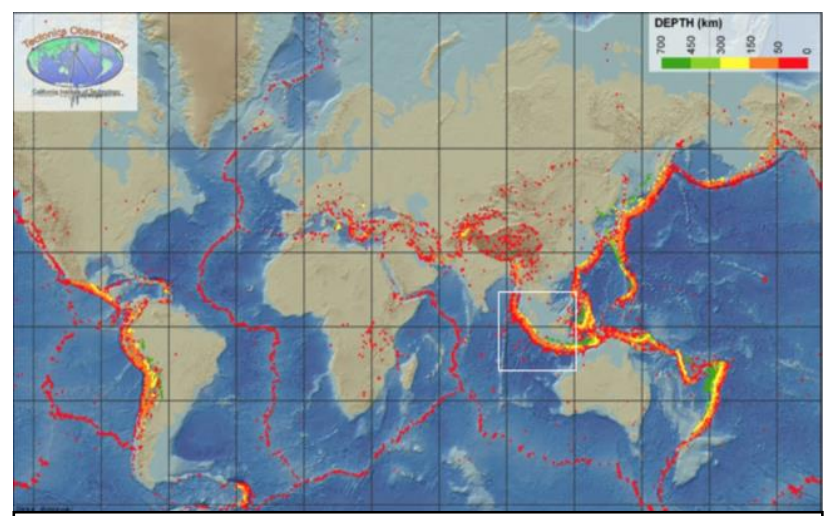

Figure 1. Global map of earthquakes with the Sumatra region outlined in white [3]

${ }^{3}$ Office of Public Works and Spatial Planning of Aceh Province, Geuceu Kayee Jato, Banda Raya, Banda Aceh City, Aceh 23232 , Indonesia. E-mail: fadila.maimun@gmail.com 
Although almost impossible to imitate real situations, simulations practically could minimize the various negative consequences, providing us input and insights for strengthening evacuation strategies. This simulation will be presented in Agent Based Modeling and Simulation (ABMS). The simulation will simulate several evacuation scenarios with an output: estimate evacuation time or time needed by the people or agents to leave the area affected by the tsunami and locate the possible congestion point within the road network.

TABLE 1.

REGION PROFILE FOR NATURAL DISASTERS FROM 1980- 2008.

\begin{tabular}{llll}
\hline Country & Disaster & Date & Killed \\
\hline Indonesia & Earthquake & 2004 & 165,708 \\
Bangladesh & Storm & 1991 & 138,866 \\
Myanmar & Storm & 2008 & 138,866 \\
China P Rep & Earthquake & 2008 & 87,476 \\
Pakistan & Earthquake & 2005 & 73,338 \\
Iran Islam Rep & Earthquake & 1990 & 40,000 \\
Sri Lanka & Earthquake & 2004 & 35,399 \\
Iran Islam Rep & Earthquake & 2003 & 26,796 \\
India & Earthquake & 2001 & 20,005 \\
Turkey & Earthquake & 1999 & 17,127 \\
\hline
\end{tabular}

\section{METHOD}

In this Chapter, steps on how developing the AgentBased Modeling for tsunami evacuation in Aceh are introduced. Those of the steps are Global environment modeling, Identifying agent types, Defining agent attributes, Agent internal behavior modeling, Defining interaction rules among agents, and Defining interaction rules between Environment and agents. Also, other important components in the tsunami evacuation model are explained in detail.

\section{II.1 Research Method of Agent Based Modeling}

The development of this tsunami evacuation modeling refers to [8], which contains of six activity groups.

- Global environment modeling.

- Identifying agent types.

- Defining agent attributes.

- Agent internal behavior modeling.

- Defining interaction rules among agents.

- Defining interaction rules between Environment and agents.

Based on Figure 2 the keys in developing accurate model are identifying the agents, accurately specifying their behaviors, and appropriately representing agent interactions. The method of creating an agent-based model was initially achieved by defining the agent types (classes) along with their attributes. Agents have role as the decisionmakers, whether they are individual, organization or automated. If the agents are identified, the behavior of the agent is determined. An agent-based model also consists of agent relationships. Such relationship adjoins methods to monitor which, when and how the agents interact with other agents or the environment.

In addition, NetLogo will also be used to test the tsunami evacuation as long as with its effects on the road network. Netlogo is a high level integrated framework for modeling via agent-based programming language [9].

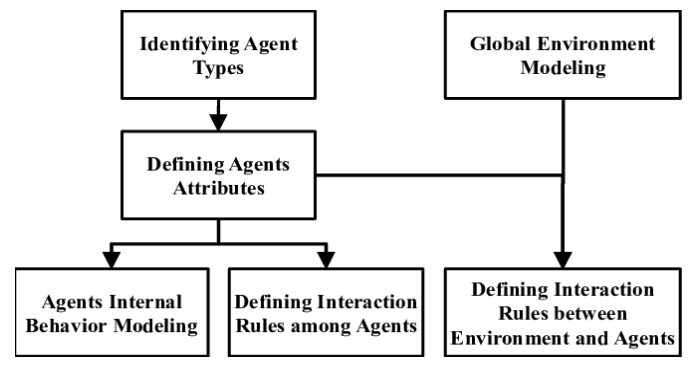

Figure 2. Research Method of Agent Based Simulation and Modeling [8]

The most complex part of evacuation modeling is primarily due to the interactions between the agents that presents the behavior in encountering emergency situation in the whole system. Furthermore, with these benefits, NetLogo's GIS compatibility further confirms the use of this platform to model and simulate the evacuation dynamics at a community level, from engineering to sociology study [9].

It must be noted that the simulation developed in this research focuses only on the pattern of people evacuation from tsunami, and identifies the congestion or bottleneck. The main question is: how long does it take for people to leave the area swept by tsunami optimally? What about the congestion, is it possible? This research will not mention the effects of the tsunami threat, and the direct effects of the earthquake on the population or the physical environment. However, the ABM platform will allow future work to extend to a multi-hazard model. The behavior of the agent is believed to be autonomous and heterogeneous, since their decisions are affected directly by their surrounding environment and interactions. To make it more simple, during evacuation, agents are believed to not change their mode, thus an agent who begins to save their life by car will not change their mode to on foot and vice versa. In the purposes of evaluating the network instability, it is believed that all agents want to be rescued, while past observations have shown that a small proportion of people have chosen to stay [9][10][11].

\section{II.2 Global Environment Modeling}

In this simulation, the artificial environment is made from the components of Global Environment including houses, shelter, road and junction layer. The raw data of location, properties of road network, shelter, building and agents used in the simulation are created from ArcGIS [12] geographic databases which later are stored in GIS files. Later, the GIS files saved in shape file (.shp) extension is used in NetLogo with the following command:

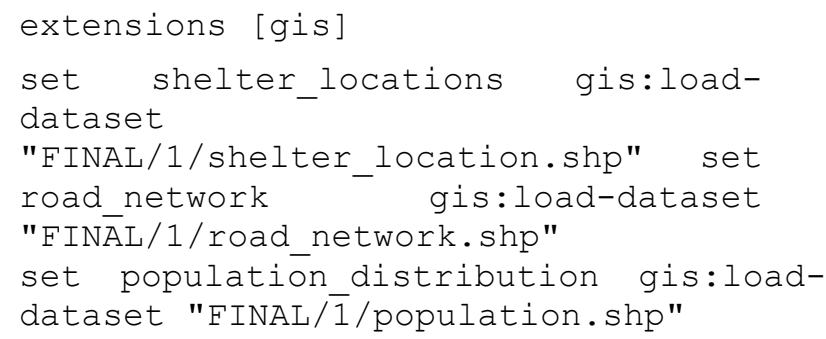




\section{II.3 Identifying Agent Types}

In Agent-Based Modeling and Simulation (ABMS), the main role of the agents are illustrating the human social behavior and making individual decisions [12]. Each agent evaluates his/her situation independently and makes an evacuation decision based on a set of rules [13]. Subsequently, in the implementation of ABMS in EMCAS (Electricity Market Complex Adaptive System), an agentbased electricity market simulation model is made to identify the market consolidation and deregulation and to understand the effect of a competitive market on electricity prices, availability, and reliability [14][15]. EMCAS agents are the participants in a restructured electricity market including: customer, distribution company, demand agent, transmission company, independent system operator, and electric power generation company [15]. In the evacuation simulation, Types of agents are individuals who head to the shelter location known as evacuees (pedestrian and car agent).

\section{II.4 Identifying Agent Attributes}

In ABMS, an agent is different from the other agent [8]. During the simulation, agent attributes can be static, and does not change or even dynamic, changeable as the simulation occurs. For example, an agent is named as a static attribute then a dynamic attribute is an agent's memory of his past interactions [8]. The example of static attributes in our tsunami evacuation simulation, an agent will have their initial names or id, destination, and etc. Meanwhile, the dynamic agent will have speed, current location, and status.

In this simulation, the evacuation process start when time (t) equal to zero. The simulation platform will breed agents
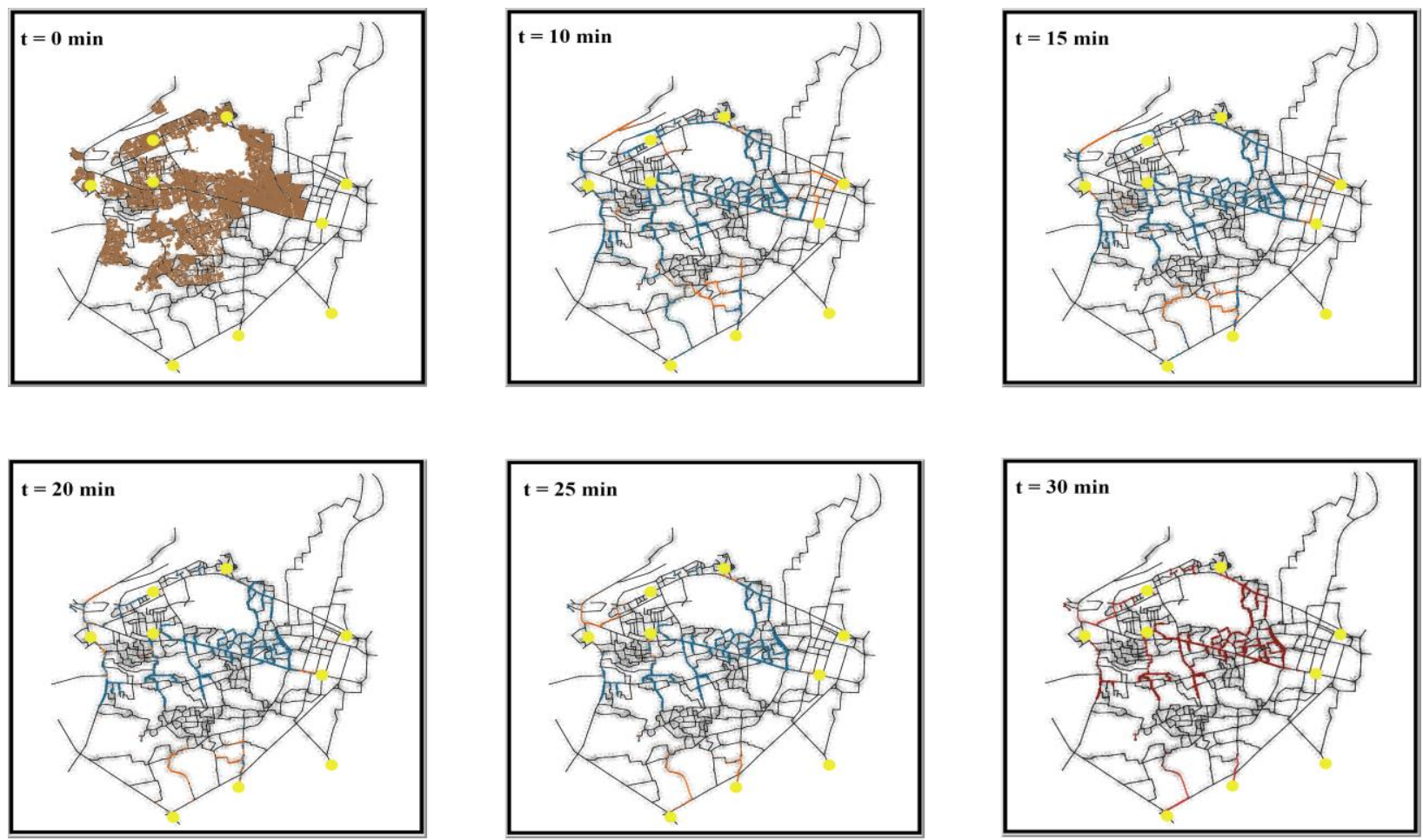

Figure 3. Example of the Simulation Progression with attribute such as current location, speed and decision. Upon reaching the closes road network, Agents will change their decision attribute to pedestrian or car agent. Once the agents choose the decision, their attributes will change following the new attribute of their decisions. For example, Pedestrian agents will have attributes such as current location, shelter, speed and path. These of their attribute are important on assessing the final result of the evacuation success rate and casualty in the evacuation simulation.

\section{II.5 Defining Interaction Rules between Agent and Environment}

This simulation starts when the shock caused by the earthquake ends $(t=0)$. In Figure 3, all agents scattered in the simulation environment will start moving towards the nearest road network. Once they interacted with the nearest road, the agent will have the option to evacuate by car or walk to the designated shelter location. Pedestrian agents will walk to the nearest shelter location, they will not interact with one another. As for Car Agents, they will interact by following the Car-following behavior so that the possibility of a collision is eliminated. After some time, all agents who make it to the location of the shelter within the time limit will change their status to evacuated while those who are not yet in the shelter will change to not evacuated (casualty).

\section{II.6 Model Components}

This simulation essentially consists of four model building blocks: population distribution, road network, shelter and casualty model, each is explained below. 
that evacuation planning is being considered for a particular time period is also of great significance.

Night time is claimed to be the best scenario for performing the evacuation in the simulation. The key reason to select the night scenario is to maximize the effects of an evaluation of the road network. In addition, simulation using night scenarios will raise people's awareness. Therefore, earthquakes and tsunamis occurred at night that is known to be people's most vulnerable moment. Although this scenario is not entirely plausible due to the fact that catastrophe will also occur during the day, this is considered true for the purpose of road network evaluation. This simulation employed census-based population data [16] of each sub-district.

\section{II.6.2 Road Network Model}

In this simulation, the road network model is obtained in the form of shapefiles from ArcGIS data which are later used to simulate the route. For this simulation the Shape file was used as an input to build a road network. In reaching the nearest shelter location, all agents are expected to follow this road network. In this model simulation, the use of alternative paths or shortcuts is forbidden. It is also generally assumed that all roads have two-way direction, since there is tendency that people will ignore traffic regulation during the disaster. When the earthquake stops, or is equal to zero in our model time, all agents should go to the nearest road, then they will choose three options for evacuation in the simulation model.

\section{II.6.3 Shelter Location}

Following the destructive tsunami that occurred in 2004 [4], the government of Banda Aceh has particularly planned and constructed four Tsunami Vertical Evacuation (TVE) buildings or escape buildings in the coastal communities region that experienced near-total destruction and would be the hardest to evacuate in the event of a potential tsunami [17].

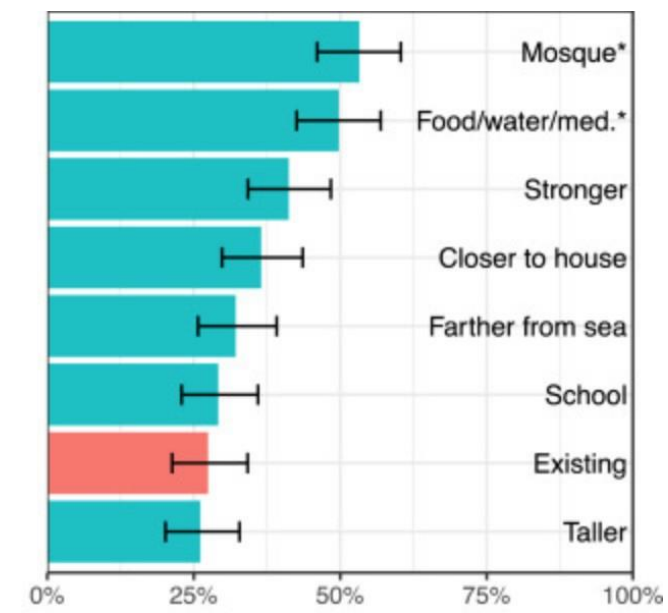

Figure 4. Survey result regarding the choice of alternative evacuation buildings choices [18].

Based on the result of survey conducted by [18] about community living near tsunami vertical evacuation (TVE) buildings, it shows that they specifically prefer horizontal evacuation, in which only 26 percent were rescued to a TVE site, while the remaining 74 percent were rescued horizontally. It means that when a tsunami happens people often going to evacuation points which are flat or inland hills as an option. Such result is confirmed by the result of other survey on the choice of alternative evacuation buildings by [18] in Figure 4.

Therefore, there are four evacuation buildings including the Grand Mosque, the Tsunami Museum, and three inland hills chosen as designated locations for shelter.

\section{II.6.4 Casualty}

The tsunami that occurred in 26 December of 2004 arrived at Banda Aceh City 20-40 minutes after earthquake of M9.2 with the height of waves reached $10-15 \mathrm{~m}$ causing widespread damage in about half of the city hitting downtown [19] [20]. Another paper reported that the tsunami arrived between 21 [21] and 65 minutes [22] after the earthquake occurred, with the average arrival times calculated as $30 \mathrm{~min}$ [23] or $35 \mathrm{~min}$ [24].

Ron Harris proposed (20/20/20 principle) a useful concept to respond a potentially tsunami situation [25]. This principle stated that when an earthquake has been going on for around 20 seconds, people have 20 minutes to evacuate (Tsunami Velocity), and must find a location with 20 meters (run-up wave) high. Since this simulation does not include the tsunami model, the casualty model will be more closely examined by examining the number of agents that succeed and fail to enter the shelter position within a certain time period. This simulation proposed 30 minutes after the initial earthquake as maximum evacuation time. The agent who reaches the shelter successfully before 30 minutes will be marked as surviving, while the others who could not reached the location within the specified maximum time will be marked as casualty. This idea may not represent an accurate mortality rate; however, this gives us a fair estimate of mortality rate for comparative purposes and for evaluation of the transportation network.

\section{II.6.5 Agent Decisions}

The Road Network Model has explained that to analyze the effect of agents in the evacuation process, local resident agents are presumed to know the direction and shortest path to the nearest evacuation points from the point at which they are situated at the start of the simulation. The nearest evacuation places for each agent and the shortest routes are determined using the $\mathrm{A}^{*}$ algorithm [26]. This statement was also implemented in the context of research on tsunami evacuation in Padang, Indonesia [27].

In addition, each agent gets out of their building and then goes to the nearest lane. When the agent has hit the nearest road, he has three decisions to choose. These three decisions are based on the premise that each agent is not in their vehicle or car during the simulation in which it is whether they are inside or outside the building. When the agent is inside the building, he will rescue himself to the designated shelter location.

The two decisions agents have are: Decision 1 is Horizontal Evacuation by on foot. When the agent chooses this decision, it means that the agent knows the best path to arrive at the shelter. Meanwhile, Decision 2 is horizontal evacuation by car. Similar to Decision 1, when the agent will take a car once they reaches the nearest road and head straight to the shelter spot. However, in the actual evacuation situation, some local authorities advised people not to use cars while evacuating themselves [28], since the 
road capacity will be limited due to high population density. Complete traffic queues are likely to occur if people attempt to evacuate themselves by car, and in the end there is a risk that people will abandon their cars and escape on foot. Within this simulation, the option of evacuation by car is still considered, as it is important to test which areas would be affected by traffic congestion. However, in this research, car speed (very small possible) and carpedestrian contact are ignored.

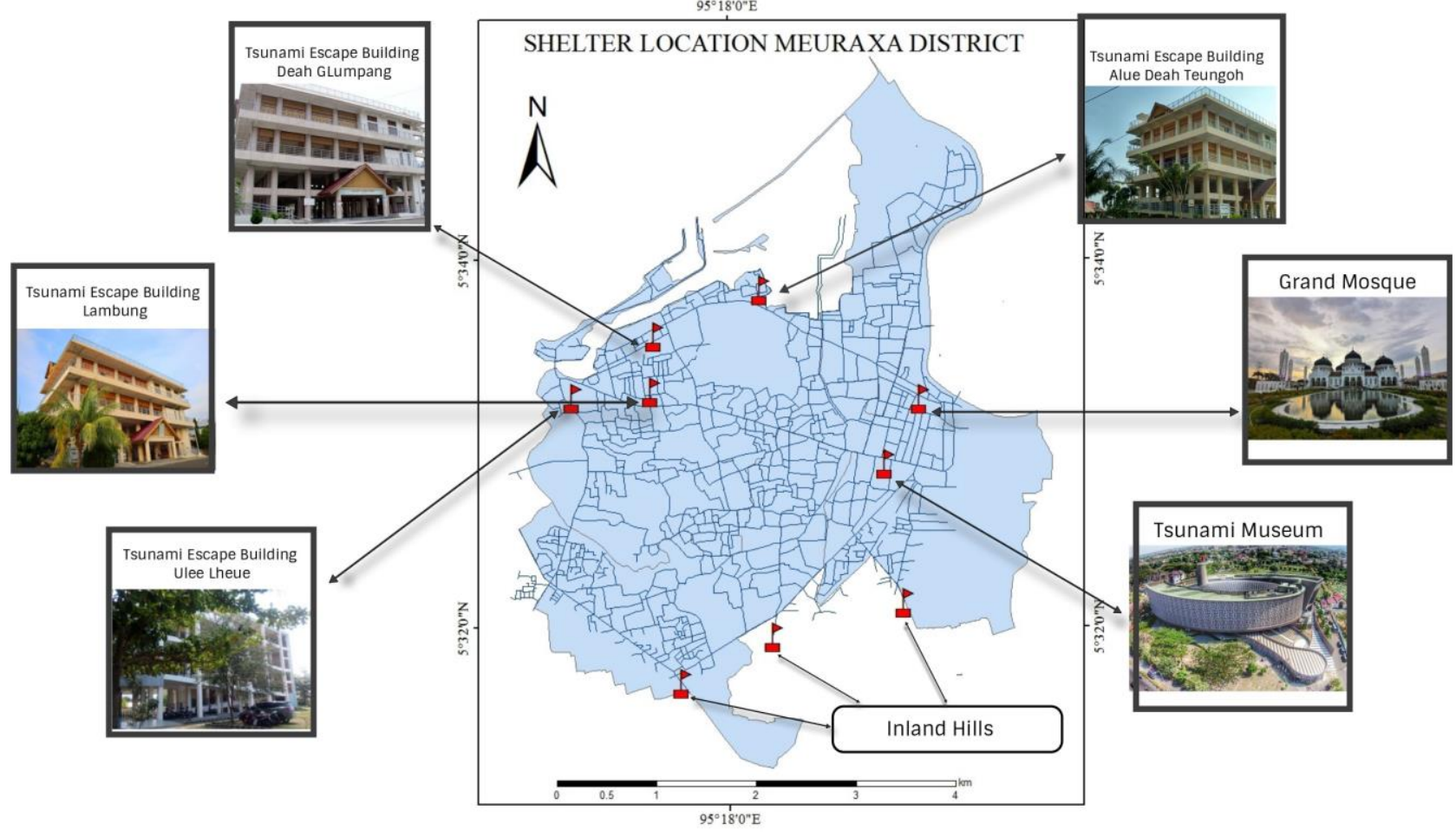

Figure 5. Shelter location for evacuation destination of tsunami evacuation simulation.

The number of agents who select either Decision 1 or 2 is presented in percentage. For example, in this simulation, 70 percent of the agent will select Decision 1, while the remaining 30 percent will select Decision 2. The social interaction of the agents in our simulation is also restricted, so that agents do not form any social interaction such as traveling in a group or using 1 car with 3 or 4 people inside. However, social interaction is considered for future development.

\section{II.6.6 Vehicular Movement}

Traffic condition where the road is in full capacity needs to be modeled aiming to evaluate transport network of the tsunami evacuation environment. The full capacity is defined as when the road is used by high number of vehicles.

Kerner et al. [29] implemented three requirements for the design of the vehicles: macro, micro, and macro. Macroscale is characterized by the volatility of the governing equations in full capacity traffic conditions [29]. Microscale depicts the vehicles as individual 'particles,' providing them some control to reflect the individual actions for their mutual interaction. The global traffic parameters are caused by these interactions and are thus observed instead of being modelled [29]. Meso-scale is between the two scales in which it models the traffic 'particles' individually but simplifies their relationship such that macroscopic activities which are allocated tot hem in some part of the network (e.g. at intersections) [29]. For this simulation, therefore, a Meso-scale model is chosen to be able to simulate the large number of vehicles and, at the same time, be compatible with the real traffic volume.

To capture the specification of this Meso-scale, the model that follows the car is interpreted as a basis for vehicle motion. The car following model by [30] measuring the rate of acceleration or deceleration of the vehicles taking into account the time difference between a front vehicle and another subsequent one. The most essential parameters for vehicle motion are acceleration and deceleration, which can be calculated using the following equation

$$
\begin{gathered}
\alpha_{n+1}^{t+\delta t}=\left[\frac{\alpha_{l, m}\left(\nu_{n+1}^{t}\right)^{m}}{\left(\chi_{n}^{t}-\chi_{n+1}^{t}\right)^{l}}\right]\left(\nu_{n}^{t}-\nu_{n+1}^{t}\right) \\
\alpha=\frac{V_{f}}{K j}
\end{gathered}
$$

On the basis of the above equation, $\alpha$ is defined as a sensitivity coefficient which can be obtained by dividing free flow rate (Vf) with jam density $(\mathrm{Kj})$, as can be seen in equation 2.2. Therefore, the parameters are dynamic, and with empirical data can be measured. Additionally, the parameter correlates linearly with the spectrum of accelerations and decelerations determined from the model that drives the vehicle. Furthermore, it needs to be fairly and objectively distributed.

In this stimulation, the maximum driving speed is set to $35 \mathrm{mph}$ while the acceleration and deceleration of the vehicles is set to $5 \mathrm{ft} / \mathrm{s}^{2}$ and $25 \mathrm{ft} / \mathrm{s}^{2}$ respectively. The condition is designed so that the car will have to stop if the leading car is less than $6 \mathrm{ft}$ away so after that the car will have to decrease the speed in the next second so as not to 
get closer to the leading car. Such condition is designed to prevent cars from collision.

\section{II.6.7 Pedestrian Movement}

Agents will be pedestrians if they choose horizontal evacuation by foot after reaching the road. Pedestrian movement is an essential variable that pedestrians need to travel to the shelter location because evacuation speed is another significant variable that regulates the evacuation of hazards [31]. The average walking speed during an emergency situation is set conservatively to $4 \mathrm{feet} / \mathrm{s}$ [32]. Each pedestrian will be assigned with a constant walking speed during the simulation.

Figure 6. shows that the fastest age class in normal conditions is the youth $(1.04 \mathrm{~m} / \mathrm{s})$, followed by the adults $(1.00 \mathrm{~m} / \mathrm{s})$. The slowest age class, on the other hand, is the older groups at $0.84 \mathrm{~m} / \mathrm{s}$, with a 19.2 percent difference against the Young. Meanwhile, the Middle-Aged Adult class has $0.99 \mathrm{~m} / \mathrm{s}$.

In this simulation, to capture the characteristics of pedestrians that are defined as elderly, children, and young pedestrians (fast walkers), this study proposed walking speed that follow the normal distribution with mean set to be $1.21 \mathrm{~m} / \mathrm{s}$ and the normal distribution's standard deviation is set at $0.2 \mathrm{~m} / \mathrm{s}$.

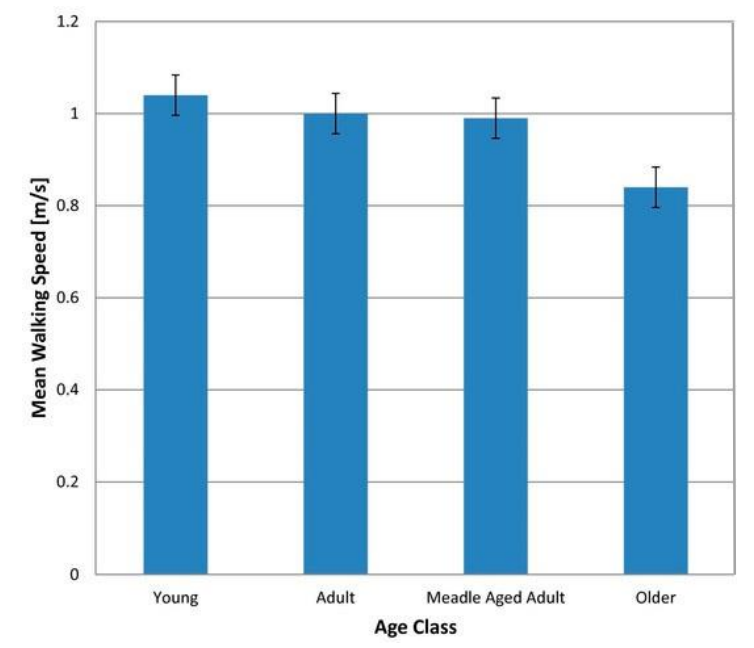

Figure 6. The Graphic of Average Walking Speed by Age Category [33]

\section{RESUlTS AND DISCUSSION}

In this Result and Discussion, all factors that have influence on the agent behavior was evaluated. Various factors could affect the evacuation rate of evacuation planning. Therefore, such factors like percentage of pedestrian, car, average walking speed and maximum driving speed were assessed under different control parameters. Furthermore, by assessing those of different parameters such an optimal evacuation plan that will minimize the mortality rate and maximize evacuation rate could be extracted. Ultimately, on the Integrated Analysis of this chapter, the recommendations of city planning are introduced.

\section{III.1 Decision Choices}

In this simulation, the agent's evacuation mode choices are distributed by varying the percentage of the agents choosing particular decision choices (car or pedestrian). At the beginning of the simulation, agents are walking to the nearest road network, upon reaching the road, agents are given the option to choose evacuation by foot (Pedestrian) or by car (Car). The variations of the percentage are as following:

$-90 \%$ Pedestrians $-10 \%$ Cars

$-80 \%$ Pedestrians $-20 \%$ Cars

$-70 \%$ Pedestrians $-30 \%$ Cars

$-60 \%$ Pedestrians $-40 \%$ Cars

$-50 \%$ Pedestrians $-50 \%$ Cars

$-40 \%$ Pedestrians $-60 \%$ Cars

$-30 \%$ Pedestrians $-70 \%$ Cars

$-20 \%$ Pedestrians $-80 \%$ Cars

$-10 \%$ Pedestrians $-90 \%$ Cars
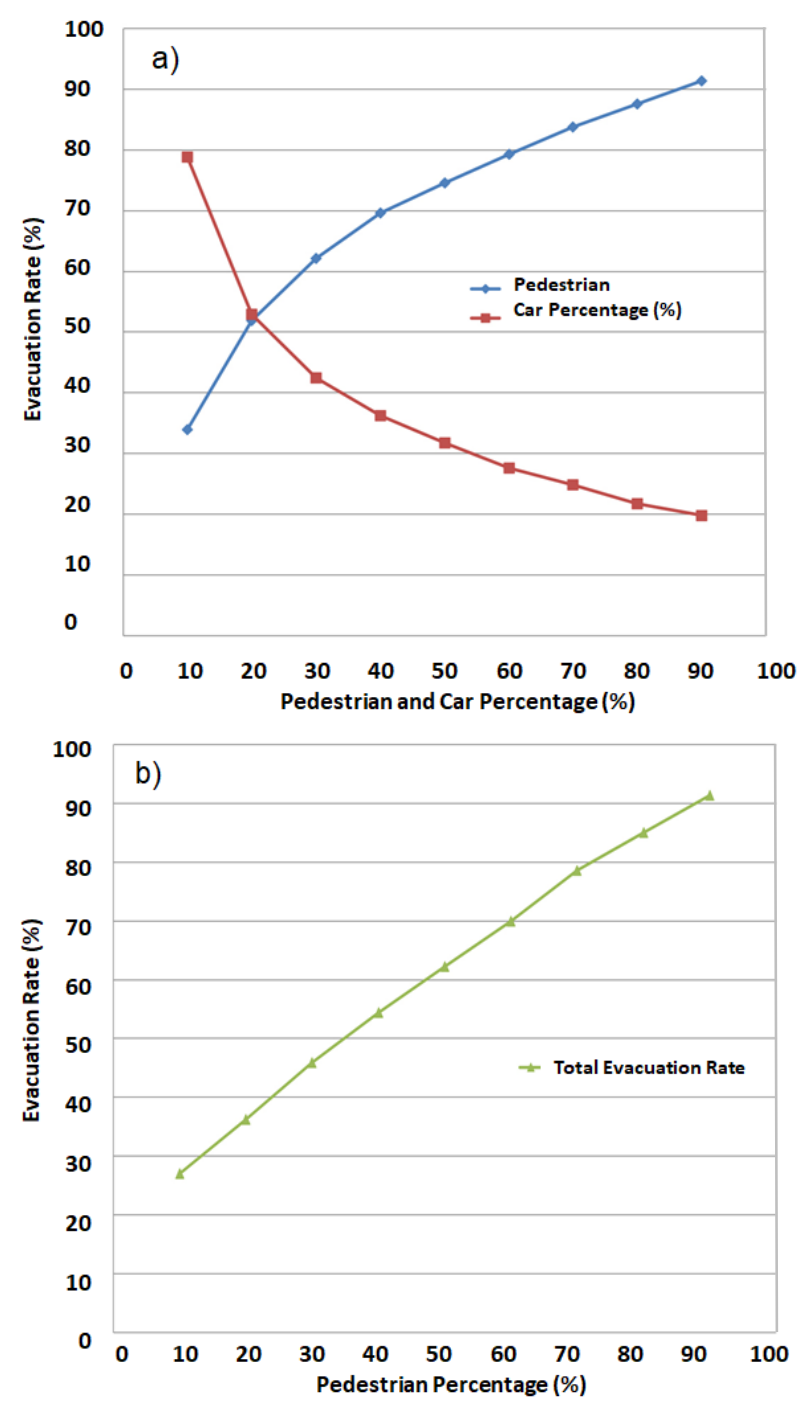

Figure 7. Impact of Pedestrians and Cars Percentage on Evacuation Rate

The different control parameters are introduced to each agent every time the simulation runs. The variations of percentage are run 10 times and the average of the evacuation rate are extracted to the plot graph as shown in Figure 7.

As shown in the Figure 7 (b), the green curve on Total Evacuation Rate showed the contribution of pedestrian percentage on the evacuation rate. In Figure 7 (a), the evacuation rate of cars shown in red curve decreased exponentially as the percentage of the car increased in the population, since the traffic jam or congestion makes all the cars stop in the road as the time passes by. On the other 
hand, the evacuation rate of pedestrians shown in blue curve linearly increases if the amount of the agent which is evacuated by foot is being escalated.

Furthermore, in order to discover the average number of people that could evacuate, this simulation was deploying $100 \%$ to $0 \%$ pedestrians on the total population as shown in Figure 8. In $100 \%$ pedestrians scenarios, more than ten agents per second are being evacuated. In other hand, in $0 \%$ pedestrian scenario, the amount of agents is decreased significantly with less than two agents per second. From this analysis, the evacuation rate of the total populations is dependent on the percentage of pedestrians. The correlation of the evacuation rate with the percentage of cars is in the opposite direction which means if the percentage of cars is higher, the total evacuation rate of the total population is declining.

\section{III.2 Impact of Different Walking Speed}

The impact of different average walking speed on the evacuation rate is also worth to be considered. Therefore, in this analysis the different average walking speeds parameters were introduced on the simulations. This parameter ranges from $3.5 \mathrm{ft} / \mathrm{s}$ to $6 \mathrm{ft} / \mathrm{s}$ on every variation of the pedestrian's percentage.
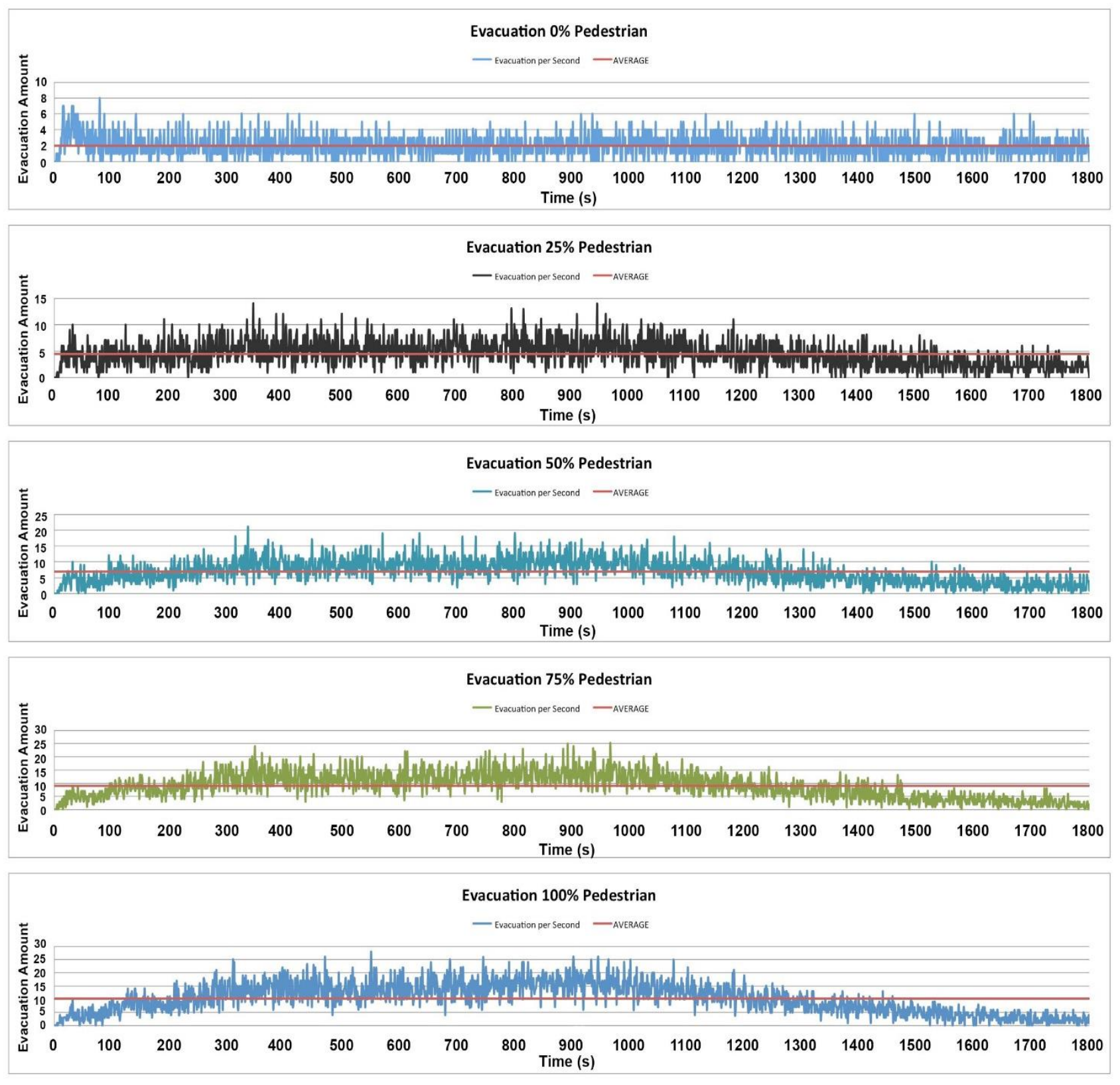

Figure 8. Evacuation Rate per Second 


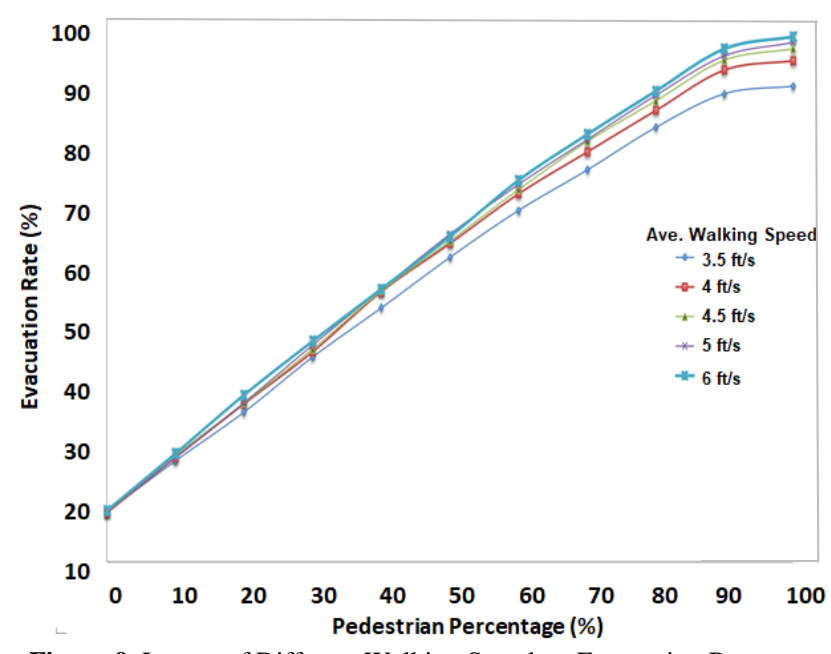

Figure 9. Impact of Different Walking Speed on Evacuation Rate

As expected, Figure 9 showed that the average walking speed has a strong influence on the evacuation rate. The evacuation rate increases as the Pedestrians increase the walking speed. Increases in the walking speed from 3.5 to $6 \mathrm{ft} / \mathrm{s}$ could increase the evacuation rate by $8 \%$ in the $100 \%$ Pedestrian scenario.

Normally, in dangerous situations people tend to walk faster than usually to save their lives. As confirmed with the result of simulation using average walking speed by 6 $\mathrm{ft} / \mathrm{s}$, the graphic shows that the probability of the evacuation rate is higher than other average walking speed. On the other hand, this simulation also certifies that moderate walking speed by $4 \mathrm{ft} / \mathrm{s}$ represents a high enough evacuation rate with $90 \%$. If we compare with the high average walking speed $(6 \mathrm{ft} / \mathrm{s})$, the difference of the evacuation rate is not significant. Therefore, the moderate walking speed ( $4 \mathrm{ft} / \mathrm{s}$ ) can be considered as a reference for average walking speed in disaster situations.

\section{III.3 Impact of Different Driving Speed}

As shown in the Decision Choices analysis, the car percentage indeed affects the evacuation rate of given scenario. The different Maximum Driving Speed on the evacuation scenario is considered as important parameters. In this study, the parameter ranges from 5 to $80 \mathrm{mph}$ are initiated on every scenario of pedestrian percentage.

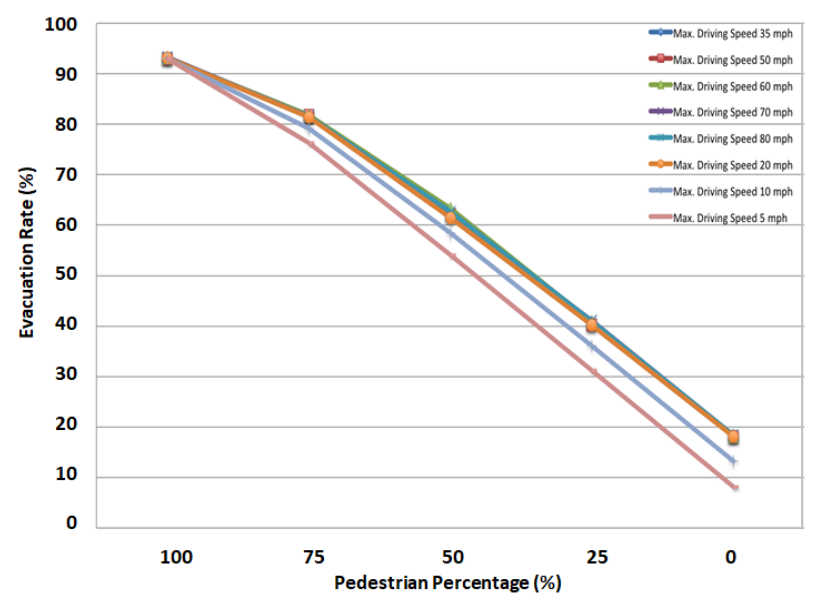

Figure 10. Impact of Different Driving Speed on Evacuation Rate

Figure 10 shows that, if different maximum driving speeds are at the range of $20 \mathrm{mph}$ or higher, it makes no different impact on the evacuation rate. Table 2 shows that different maximum driving speeds above $20 \mathrm{mph}$ on the scenario of pedestrian percentage have similar evacuation rate percentage. This situation is supported by the real fact, when the road network is in a congestion or stuck state, the mobility of the cars is very limited, therefore every car in the road network is unable to reach their maximum driving speed. However, for the maximum driving speed below $20 \mathrm{mph}$ has an impact on increasing the evacuation rate. Based on this simulation, the maximum driving speed in disaster situations is recommended by $20 \mathrm{mph}$.

TABLE 2.

EFFECT OF DIFFERENT MAXIMUM DRIVING SPEED ON EVACUATION RATE

\begin{tabular}{l|cccccccc}
\hline \multirow{2}{*}{ Pedestrian Percentage (\%) } & \multicolumn{8}{|c|}{ Evacuation Rate on Max. Driving Speed } \\
\cline { 2 - 9 } & 5 & 10 & 20 & 35 & 50 & 60 & 70 & 80 \\
\hline 75 & 76.26 & 79.17 & 81.36 & 81.44 & 81.80 & 81.75 & 81.53 & 81.50 \\
50 & 54.06 & 58.47 & 61.38 & 62.69 & 62.14 & 63.35 & 62.16 & 62.68 \\
25 & 31.25 & 36.11 & 40.25 & 40.73 & 40.21 & 40.86 & 41.02 & 40.92 \\
0 & 8.16 & 13.20 & 18.13 & 18.30 & 18.15 & 18.17 & 18.36 & 18.36 \\
\hline
\end{tabular}

\section{CONCLUSION}

This study on tsunami evacuation using agent-based modeling presented and evaluated the different control parameters that will affect the evacuation rate. The different control parameters such as evacuation mode, percentage of car and pedestrian, walking speed and driving speed confirmed their significance on the evacuation planning. A simulation designed in NetLogo Environment used to assess the importance of those control parameters on the evacuation scenario. The result of this tsunami evacuation simulation shows that the decision choices on the evacuation mode are highly correlated to the evacuation rate. There is a typical choice that leads to the higher evacuation rate, the choice is by maximizing the pedestrian agents on the population. Walking speed has significant importance and impact on the evacuation rate. Moderate walking speed ( $4 \mathrm{ft} / \mathrm{s})$ is recommended as reference for walking speed in disaster situations. Driving speed also has a significant impact on the evacuation rate if we keep the limits at $20 \mathrm{mph}$. Since the maximum driving speed higher than $20 \mathrm{mph}$ has no impact on the evacuation rate.

\section{REFERENCES}

[1] H. Darman, An outline of the geology of Indonesia. Lereng Nusantara, 2000.

[2] F. Wafda, R. W. Saputra, Y. Nurdin, and K. Munadi, "Agentbased tsunami evacuation simulation for disaster education," in International Conference on ICT for Smart Society, 2013, pp. $1-4$.

[3] W. Bank, "Preparing Indonesia for Future Natural Hazards."

[4] H. Kanamori, "Lessons from the 2004 Sumatra-Andaman earthquake," Philos. Trans. R. Soc. A Math. Phys. Eng. Sci., vol. 364, no. 1845, pp. 1927-1945, 2006.

[5] "Indonesia, Maldives, Sri Lanka: Earthquake and Tsunami OCHA Situation Report No. 18." [Online]. Available: https://reliefweb.int/report/indonesia/indonesia-maldives-srilanka-earthquake-and-tsunami-ocha-situation-report-no-18. E.-D. I. D. Database, "Region Profile for Natural Disasters from 1980 - 2008."

[7] K. H. Van Dam, I. Nikolic, and Z. Lukszo, Agent-based modelling of socio-technical systems, vol. 9. Springer Science \& Business Media, 2012.

[8] C. M. Macal and M. J. North, "Tutorial on agent-based 
modeling and simulation," in Proceedings of the Winter Simulation Conference, 2005., 2005, pp. 14-pp.

[9] U. Wilensky, "NetLogo. Evanston, IL: Center for connected learning and computer-based modeling, Northwestern University." 1999

[10] E. Mas, A. Suppasri, F. Imamura, and S. Koshimura, "Agentbased simulation of the 2011 great east japan earthquake/tsunami evacuation: An integrated model of tsunami inundation and evacuation," J. Nat. Disaster Sci., vol. 34, no. 1, pp. 41-57, 2012.

[11] E. Mas, F. Imamura, and S. Koshimura, "An agent based model for the tsunami evacuation simulation. A case study of the 2011 great east Japan tsunami in Arahama town," 2012.

[12] "Redlands ESRI. 'ArcGIS desktop: release 10'. In: Environmental Systems Research In- stitute, CA (2011).” .

[13] R. J. Dawson, R. Peppe, and M. Wang, "An agent-based model for risk-based flood incident management," Nat. hazards, vol. 59, no. 1, pp. 167-189, 2011.

[14] M. North, G. Conzelmann, V. Koritarov, C. Macal, P. Thimmapuram, and T. Veselka, "E-laboratories: agent-based modeling of electricity markets.," Argonne National Lab., IL (US), 2002.

[15] V. S. Koritarov, "Real-world market representation with agents," IEEE Power Energy Mag., vol. 2, no. 4, pp. 39-46, 2004.

[16] "Statistics of Banda Aceh City. Kecamatan Meuraxa Dalam Angka 2018."

[17] M. Munirwansyah, H. Munirwan, M. Irsyam, and R. P. Munirwan, "Escape hill development as a strategy to improve urban safety after earthquake and tsunami Aceh 2004 based on regional planning and geotechnical aspect," in Journal of Physics: Conference Series, 2020, vol. 1572, no. 1, p. 12030.

[18] J. W. McCaughey, I. Mundir, P. Daly, S. Mahdi, and A. Patt, "Trust and distrust of tsunami vertical evacuation buildings: Extending protection motivation theory to examine choices under social influence," Int. J. disaster risk Reduct., vol. 24, pp. $462-473,2017$

[19] N. K. Co, "The Study On The Urgent Rehabilitation And Reconstruction Support Program For Aceh Province And Affected Areas In North Sumatra (Urgent Rehabilitation And Reconstruction Plan For Banda Aceh City) In The Republic Of Indonesia," 2012.

[20] F. Lavigne et al., "Reconstruction of tsunami inland propagation on December 26, 2004 in Banda Aceh, Indonesia, through field investigations," Pure Appl. Geophys., vol. 166, no. 1, pp. 259-281, 2009.

[21] J. McCloskey et al., "Tsunami threat in the Indian Ocean from a future megathrust earthquake west of Sumatra," Earth Planet. Sci. Lett., vol. 265, no. 1-2, pp. 61-81, 2008

[22] H. Taubenböck et al., "“ Last-Mile' preparation for a potential disaster-Interdisciplinary approach towards tsunami early warning and an evacuation information system for the coastal city of Padang, Indonesia," Nat. Hazards Earth Syst. Sci., vol. 9, no. 4, pp. 1509-1528, 2009

[23] A. Muhari et al., "Tsunami mitigation efforts with pTA in west Sumatra province, Indonesia," J. Earthq. Tsunami, vol. 4, no. 04, pp. 341-368, 2010.

[24] J. C. Borrero, K. Sieh, M. Chlieh, and C. E. Synolakis, "Tsunami inundation modeling for western Sumatra," Proc. Natl. Acad. Sci., vol. 103, no. 52, pp. 19673-19677, 2006.

[25] R. Harris, "Foundation News: Tsunami preparedness in Java, Indonesia," Lead. Edge, vol. 36, no. 3, pp. 204-205, 2017.

[26] H. Reddy, "PATH FINDING-Dijkstra's and A* Algorithm's," Int. J. IT Eng., pp. 1-15, 2013.

[27] M. Di Mauro, K. Megawati, V. Cedillos, and B. Tucker, "Tsunami risk reduction for densely populated Southeast Asian cities: analysis of vehicular and pedestrian evacuation for the city of Padang, Indonesia, and assessment of interventions," Nat. hazards, vol. 68, no. 2, pp. 373-404, 2013.

[28] "Tsunami Evacuation Plan for Kamakura City," Kamakura City Office.

[29] B. S. Kerner, Introduction to modern traffic flow theory and control: the long road to three-phase traffic theory. Springer Science \& Business Media, 2009.

[30] R. Herman, E. W. Montroll, R. B. Potts, and R. W. Rothery, "Traffic dynamics: analysis of stability in car following," Oper. Res., vol. 7, no. 1, pp. 86-106, 1959.

[31] N. J. Wood and M. C. Schmidtlein, "Anisotropic path modeling to assess pedestrian-evacuation potential from Cascadia-related tsunamis in the US Pacific Northwest," Nat. Hazards, vol. 62, no. 2, pp. 275-300, 2012.

[32] R. L. Knoblauch, M. T. Pietrucha, and M. Nitzburg, "Field studies of pedestrian walking speed and start-up time," Transp. Res. Rec., vol. 1538, no. 1, pp. 27-38, 1996.

[33] F. Pinna and R. Murrau, "Age factor and pedestrian speed on sidewalks," Sustainability, vol. 10, no. 11, p. 4084, 2018. 